\title{
A relationship between the molar proportion of propionic acid and the clearance rate of the liquid phase in the rumen of the sheep
}

\author{
BY J. C. HODGSON* AND P. C. THOMAS \\ The Hannah Research Institute, Ayr KA6 ${ }_{5} H L$ \\ (Received 22 October 1974 - Accepted 4 December 1974)
}

\begin{abstract}
I. Four rumen-cannulated sheep were given a forage mixture (F) of chopped hay-ground, pelleted, dried grass $(92: 8, w / w)$ and two concentrate mixtures (C and $S$ ) of ground barleyground hay-flaked maize $(46: 24: 30$ and $56: 24: 20$, by wt respectively) in twenty-four hourly meals each day. Each of the diets was offered in successive periods of $16 \mathrm{~d}$ to give a feeding sequence $\mathrm{F}-\mathrm{S}-\mathrm{C}-\mathrm{S}$ for one pair of sheep and $\mathrm{C}-\mathrm{S}-\mathrm{F}-\mathrm{S}$ for the other pair.

2. The average composition ( $\mathrm{mol} / 100 \mathrm{~mol}$ ) of the mixture of short-chain fatty acids, acetic, propionic and butyric, in the rumen was respectively $70.1,18.5$ and 7.5 with diet $F$, and 55.8 , 24.8 and 13.6 with diet $C$. With diet $S$, the pattern of fermentation varied both between animals and in the same animal for different periods having either 'high' $(28-39 \mathrm{~mol} / \mathrm{roo} \mathrm{mol})$ or 'low' ( $16-21 \mathrm{~mol} / \mathrm{r} 00 \mathrm{~mol}$ ) proportions of propionic acid. On average when diet $\mathrm{S}$ followed diet $F$ there was less propionic acid in the fermentation mixture than when diet $\mathrm{S}$ followed diet $C$ (59.3 acetic, $22 \cdot 2$ propionic and 14.1 butyric as compared with $52.7,29.4$ and 13.1 respectively) but this trend was not significant and there was evidence of interactions between the feeding sequences and the individual sheep.

3. The mean concentrations of ammonia, sodium, potassium and chloride were similar for all diets but the $\mathrm{pH}$ and concentrations of calcium, magnesium and phosphorus tended to be higher and the buffering capacity lower for diet $F$ than for diets $C$ or $S$. In animals receiving diet $S$ there was no relationship between the concentrations of minerals, the pH or buffering capacity and the pattern of fermentation except for ammonia, the concentration of which was high when the molar proportion of propionic acid was low.

4. Rumen volume, outflow rate and clearance rate, determined using polyethylene glycol, were higher for diet $\mathrm{F}$ than for diets $\mathrm{C}$ and $\mathrm{S}$ but within each diet, particularly for diet $\mathrm{S}$, values varied considerably between sheep and between periods.

5. There was evidence of an interrelationship between the molar proportion of propionic acid in the fermentation products and the clearance rate, which indicated that the clearance rate may be an important factor influencing the pattern of fermentation in the rumen.
\end{abstract}

Ishaque, Thomas \& Rook (1971) found that for sheep given a diet of $(\mathrm{g} / \mathrm{kg}): 560$ ground barley, 240 ground hay and 200 flaked maize, there were wide variations in the composition of the mixture of short-chain fatty acids in the rumen between animals, or in the same animals on different occasions. In eight of their experiments animals were introduced to the experimental dict after receiving a diet of chopped hay, and in five of these experiments the mixture of fatty acids contained a low proportion of propionic acid $\left(\mathrm{r}_{3}-18 \mathrm{~mol} / \mathrm{100} \mathrm{mol}\right)$. In the remaining three experiments, and in two additional experiments where the pre-experimental diet was of ground barley, ground hay and flaked maize, the molar proportion of propionic acid was high $(28-38 \mathrm{~mol} /$ $100 \mathrm{~mol}$ ). The precise influence of the 'pre-experimental' diet on the fermentation pattern is difficult to assess because 'pre-experimental' treatments are confounded by between-animal differences.

* Present address: Biochemistry Department, Animal Diseases Research Association, MIoredun Institute, 408 Gilmerton Road, Edinburgh $\mathrm{EH}_{7} 7 \mathrm{JH}$. 
As compared with the 'high-propionic acid' type of fermentation the 'low-propionic acid' type was associated with a high ruminal breakdown of cellulose and a low rate of synthesis of bacterial protein. The simplest interpretation of these results is that the two types of fermentation reflected differences in the metabolic activity of the rumen microbes. It follows, since the experimental diet and conditions of feeding in the experimental period were standardized, that either widely divergent microbial activity occurred in the rumen under similar 'culture' conditions or that there were important differences between fermentation types in conditions in the rumen.

The activity of rumen organisms and their success in the competition for establishment in the rumen population is influenced by a wide range of factors. In vitro the active cellulolytic species have been shown to be sensitive to the concentration of organic nutrients, particularly nitrogenous compounds, and inorganic nutrients in the culture medium (Hungate, r966). In vivo improvements in cellulose digestion have been obtained by supplementing the diet with nitrogenous materials (Campling \& Freer, 1966) and with mineral mixtures (Tillman, Sirny \& MacVicar, 1954). Many organisms will thrive only within narrow limits of $\mathrm{pH}$ (see Hungate, 1966) and their viability in the rumen is influenced by the balance between the buffering capacity of the rumen fluid and the acidity of the products of fermentation. For slowly dividing organisms a further factor may be the rate of flow of fluid through the rumen. If the rate of replacement of fluid is faster than the division rate of the organisms, they may be 'washed out' of the rumen and their numbers reduced (Christiansen, Woods \& Burroughs, 1964).

The aim of the experiment reported here was to examine more fully the effects of the 'pre-experimental' diet on fermentation in the rumen of sheep given an 'experimental' diet similar to that used by Ishaque et al. (1971) and to study the possible link between variations in the pattern of fermentation with this diet and variations in the environmental conditions in the rumen. The 'pre-experimental' diets used were chopped hay-dried grass $(90: 8, \mathrm{w} / \mathrm{w})$ and ground barley-flaked maize-ground hay $(46: 30: 24$, by $w t)$. For comparative purposes determinations similar to those made in sheep receiving the 'experimental' diet were also made in animals receiving the 'preexperimental' foods.

There has been preliminary communication of some of the results (Hodgson $\&$ Thomas, 1972).

\section{EXPERIMENTAL}

\section{Animals and their management}

Four Suffolk $\times$ Masham castrated male sheep fitted with permanent rumen cannulas were used. The animals which were 3 years old and weighed about $5^{6} \mathrm{~kg}$ were housed in metabolism cages in an animal house lit artificially day and night. Food was given each day in twenty-four hourly meals by means of a device similar to that described by Minson \& Cowper ( 1966$)$ and water $(2.51 / d)$ was provided as a continuous intraruminal infusion. When required, polyethylene glycol (PEG), which was used as an inert marker, was dissolved in the water infusion at a rate of $5 \mathrm{~g} / \mathrm{l}$. 
Table I. The composition ( $\mathrm{g} / \mathrm{kg}$ dry matter) of the diets* fed to sheep

\begin{tabular}{|c|c|c|c|}
\hline & \multicolumn{3}{|c|}{ Diet } \\
\hline & $\mathrm{F} \uparrow$ & $\mathrm{C} f$ & $S \S$ \\
\hline $\begin{array}{l}\text { Dry matter }(\mathrm{g} / \mathrm{kg}) \\
\text { Nitrogen }\end{array}$ & $\begin{array}{l}915 \\
\text { I } 6.8\end{array}$ & $\begin{array}{l}895 \\
16 \cdot 8\end{array}$ & $\begin{array}{l}894 \\
17.5\end{array}$ \\
\hline Crude fibre & 329 & I10 & 114 \\
\hline Sodium & $I \cdot 5 I$ & $1 \cdot 40$ & $I \cdot 20$ \\
\hline Potassium & $19 \cdot 37$ & $6 \cdot 56$ & $6 \cdot 72$ \\
\hline Calcium & 3.73 & $3 \cdot 73$ & 3.73 \\
\hline Magnesium & $\mathrm{I} \cdot 4 \mathrm{I}$ & $\mathrm{I} \cdot \mathbf{4 I}$ & $\mathrm{I} \cdot 4 \mathrm{I}$ \\
\hline Phosphorus & $3 \cdot 22$ & 3.22 & 3.22 \\
\hline Chloride & $I \cdot 3 I$ & $I \cdot 3 I$ & $I \cdot 31$ \\
\hline
\end{tabular}

$\mathrm{F}$, forage mixture of chopped hay-ground, pelleted, dried grass $(92: 8, \mathrm{w} / \mathrm{w}) ; \mathrm{C}$ and $\mathrm{S}$, concentrate mixtures of ground barley-ground hay-flaked maize (46:24:30 and $56: 24: 20$, by wt respectively).

* All diets contained $6 \mathrm{~g}$ trace element mixture $/ \mathrm{kg}$ fresh weight containing $(\mathrm{g} / \mathrm{kg}): 0.16$ anhydrous $\mathrm{CuSO}_{4}, 3.68 \mathrm{FeSO}_{4} .7 \mathrm{H}_{2} \mathrm{O}, 0.77 \mathrm{Na}_{2} \mathrm{~B}_{4} \mathrm{O}_{7} \cdot 10 \mathrm{H}_{2} \mathrm{O}, 0.4 \mathrm{I} \mathrm{MnSO}_{4} . \mathrm{H}_{2} \mathrm{O}, 0.85 \mathrm{ZnSO}_{4} .7 \mathrm{H}_{2} \mathrm{O}, 0 . \mathrm{I}_{4} \mathrm{KI}$, $0.003 \mathrm{Co}\left(\mathrm{NO}_{3}\right)_{2} .6 \mathrm{H}_{2} \mathrm{O}, 0.003 \mathrm{MoO}_{3}$. Diets also contained $5 \mathrm{~g}$ vitamin supplement $/ \mathrm{kg}$ fresh weight containing $(/ \mathrm{kg}): 400 \mu \mathrm{g}$ retinol equivalent, $22 \mu \mathrm{g}$ cholecalciferol equivalent, $33 \mathrm{mg} \alpha$-tocopherol.

$\dagger$ Containing as a mineral supplement $\left(\mathrm{g} / \mathrm{kg}\right.$ dry matter): $0.93 \mathrm{CaCO}_{3}, 4.43 \mathrm{NaH}_{2} \mathrm{PO}_{4}, 2.36 \mathrm{NaCl}$.

$\ddagger$ Containing as a mineral supplement (g/kg dry matter): $7.34 \mathrm{CaCO}_{3}, 4 \cdot 27 \mathrm{MgCl}_{2}, 3 \cdot 85 \mathrm{NaH}_{2} \mathrm{PO}_{4}$, 2.4I NaCl.

$\S$ Containing as a mineral supplement $\left(\mathrm{g} / \mathrm{kg}\right.$ dry matter): $7.25 \mathrm{CaCO}_{3}, 3.57 \mathrm{MgCl}_{2}, 2.38 \mathrm{NaH}_{2} \mathrm{PO}_{4}$, $2 \cdot 42 \mathrm{NaCl}$.

\section{Diets}

The diets were a forage mixture (F) consisting of chopped hay-ground, pelleted, dried grass $(92: 8, \mathrm{w} / \mathrm{w})$ and two concentrate mixtures $(\mathrm{C}$ and $\mathrm{S})$ consisting of ground barley and ground hay, pelleted together, and loose, flaked maize. Diet $\mathrm{S}$ was similar in composition to the diet used by Ishaque et al. (I97I) and consisted of barleyhay-flaked maize $(56: 24: 20$, by wt). The diets were supplemented with minerals and vitamins and balanced with respect to each other in their concentrations of calcium, magnesium, phosphorus and chloride. Details of their composition and of the mineral and vitamin supplements are given in Table $\mathrm{I}$.

\section{Experimental design}

The experiment consisted of four successive periods in each of which each sheep received one of the diets at a rate of $22.5 \mathrm{~g} / \mathrm{kg}$ body-weight per $\mathrm{d}$. Two sheep received the diets in the order F-S-C-S and the other two in the order C-S-F-S. Each period was $16 \mathrm{~d}$ and from day o-day 15 of this period $\mathrm{PEG}$ solution was infused into the rumen. On days $\mathrm{I} 3$ and $\mathrm{I} 4$ samples of rumen fluid were taken at 10.30 and 15.30 hours each day and each sample analysed for PEG, chemical constituents, $\mathrm{pH}$ and buffering capacity. On day I 5 at 09. I 5 hours the PEG infusion was replaced by an infusion of distilled water. Small samples of rumen fluid were taken at 09.30 hours and at hourly intervals until $\mathrm{I} 7.3 \mathrm{O}$ hours for analysis for PEG. On day $\mathrm{I} 6$ similar samples were again taken at 09.30 hours and each hour until $\mathrm{r} 3.30$ hours. 


\section{Sampling procedure and methods of analysis}

Samples of rumen fluid were taken by suction from a point approximately $150 \mathrm{~mm}$ below the rumen cannula. Where appropriate a portion of the sample was immediately placed under liquid paraffin and used to determine $\mathrm{pH}$ and buffering capacity by the method of Emmanuel, Lawlor \& McAleese (1969); the remainder was strained through muslin. Samples of the strained fluid were analysed for ammonia by the method of Conway (1957). The residual fluid was centrifuged at $1000 \mathrm{~g}$ to remove solids and the supernatant fraction was stored at $-20^{\circ}$. The stored sample was analysed for total and individual short-chain fatty acid contents (Annison, 1954; Storry \& Millard, 1965; Youssef \& Allen, 1966), P content (Bonting, Simon \& Hawkins, I960) and $\mathrm{Cl}$ content (Davies, I938). Sodium and potassium contents were determined by flame emission spectrophotometry and $\mathrm{Ca}$ and $\mathrm{Mg}$ contents by flame absorption spectrophotometry. PEG was determined by the method of Smith (1959).

\section{Rumen volume and outflow rate}

Rumen volume and outflow rate were determined from the concentration of PEG in rumen fluid. In a previous report (Hodgson \& Thomas, 1972) volumes were calculated from the curvilinear plots of PEG concentration $v$. time. The values reported here were calculated from $\log$ plots by the procedure described by Warner (1966) and Weston \& Hogan ( 1967 ). From the volume and outflow rate the proportion of the rumen pool replaced/h was calculated. This value was termed the clearance rate.

\section{Statistical methods}

During the third period of the experiment one sheep (no. 20) became ill and was removed from the experiment, therefore results for this animal for the third and fourth periods were missing. Results for the other three sheep and for the first two periods for sheep no. 20 were subjected to a non-orthogonal analysis of variance in which the experiment was considered to consist of four treatments: $\operatorname{diet} \mathrm{F}$, diet $\mathrm{C}$, diet $\mathrm{S}$ when given in the period following diet $\mathrm{F}\left(\mathrm{S}_{\mathrm{f}}\right)$ and diet $\mathrm{S}$ when given in the period following $\operatorname{diet} \mathrm{C}\left(\mathrm{S}_{\mathrm{c}}\right)$.

\section{RESULTS}

Effects of diet and of the 'pre-experimental' diet on the composition of rumen fluid

Short-chain fatty acids. The results for the concentration and composition of the mixture of rumen fatty acids are summarized in Table 2. Differences between diets $\mathrm{F}$ and $\mathrm{C}$ and diets $\mathrm{S}_{\mathrm{f}}$ and $\mathrm{S}_{\mathrm{c}}$ in the concentration of total fatty acids were statistically significant $(P<0.05)$. Although there were considerable variations in the average composition of the mixture of fatty acids only the differences between acetic and isobutyric acids for the diets $\mathrm{F}$ and $\mathrm{C}$ were significant. This situation resulted mainly from the marked individuality of the sheep both in the molar proportions of the fatty acids in the rumen with a single diet and in the pattern of change in the proportions of fatty acids between diets. In Fig. I the molar proportions of the three main fatty acids, acetic, propionic and butyric, are shown in the order in which the diets were fed. 
Table 2. The mean concentration of total and individual short-chain fatty acids in the rumen fluid from two pairs of sheep receiving diets $F, C$ and $S$ in the order $F-S-C-S$ or $C-S-F-S$

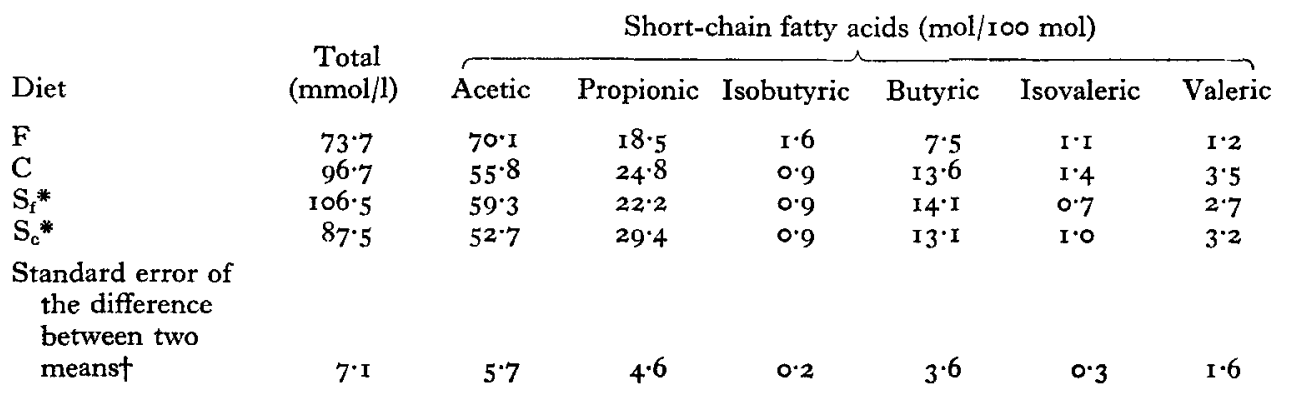

$\mathrm{F}$, forage mixture of chopped hay-ground, pelleted, dried grass $(92: 8, \mathrm{w} / \mathrm{w}) ; \mathrm{C}$ and $\mathrm{S}$, concentrate mixtures of ground barley-ground hay-flaked maize $(46: 24: 30$ and $56: 24: 20$, by wt respectively) (for details of the composition of diets, see Table 1$) ; S_{1}$, diet $S$ given in the period following $\operatorname{diet}\left[F ; S_{c}\right.$, $\operatorname{diet} \mathrm{S}$ given in the period following $\operatorname{diet} \mathrm{C}$.

* Values for three sheep.

+ Differences between diets $F$ and $C$ and between diets $S_{1}$ and $S_{c}$.
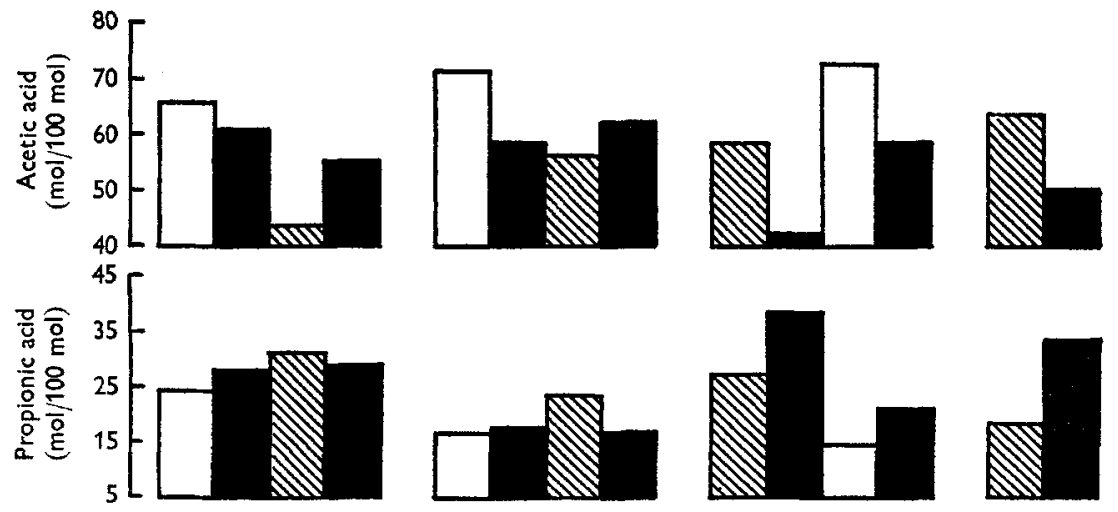

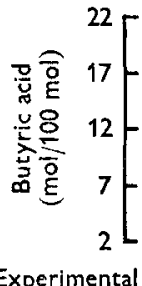

Experimenta
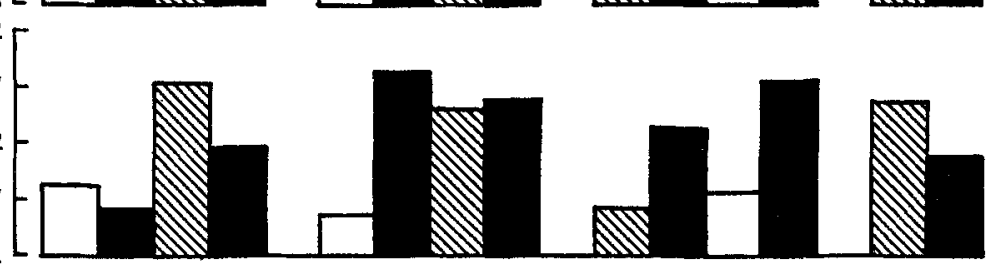

Sheep no. ...

$\begin{array}{llll}1 & 2 & 3 & 4\end{array}$

$\begin{array}{llll}1 & 2 & 3 & 4\end{array}$

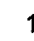

234

12

21

37

20

Fig. 1. The molar proportions of acetic, propionic and butyric acids in rumen fluid from sheep receiving diet $F(\square)$, diet $C(\mathbb{S})$ and diet $S(\square)$. Diet $F$ was a forage mixture of chopped hay-ground, pelleted, dried grass $(92: 8, w / w)$; diets $C$ and $S$ were concentrate mixtures of ground barley-ground hay-flaked maize ( $46: 24: 30$ and $56: 24: 20$, by wt respectively). For details of the composition of the diets, see Table $I$. 
Table 3. The $p H$, buffering capacity and concentrations ( $m g / l)$ of ammonia, calcium, magnesium and phosphorus in the rumen fuid from two pairs of sheep receiving diets $F, C$ and $S$ in the order $F-S-C-S$ or $C-S-F-S$

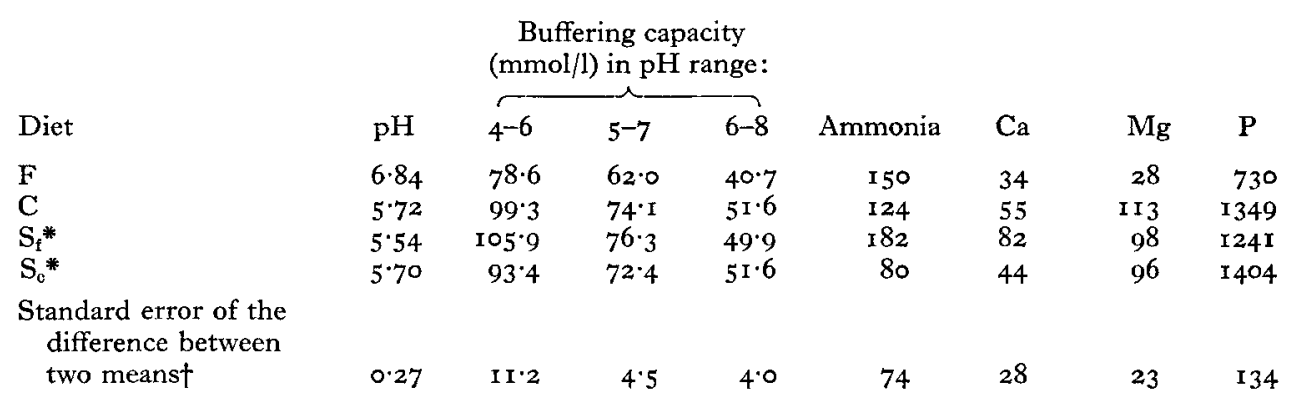

F, forage mixture of chopped hay-ground, pelleted, dried grass $(92: 8, \mathrm{w} / \mathrm{w}) ; \mathrm{C}$ and S, concentrate mixture of ground barley-ground hay-flaked maize $(46: 24: 30$ and $56: 24: 20$, by wt respectively) (for details of the composition of diets, see Table $\mathrm{x}) ; \mathrm{S}_{\mathrm{f}}$, diet $\mathrm{S}$ given in the period following $\operatorname{diet} \mathrm{F} ; \mathrm{S}_{\mathrm{c}}$, diet $\mathbf{S}$ given in the period following diet $\mathbf{C}$.

* Values for three sheep.

+ Differences between diets $F$ and $C$ and between diets $S_{1}$ and $S_{c}$.

For sheep nos. $\mathrm{I} 8$ and $2 \mathrm{I}$, where the initial diet was $\mathrm{F}$, the molar proportion of propionic acid was much less variable than for sheep nos. 37 and 20, where the initial diet was $\mathrm{C}$, but the proportion of propionic acid was consistently higher for sheep no. I 8 than for sheep no. 2r. Interestingly, for sheep no. 37, where the pattern of fermentation varied markedly, there appeared to be a relationship between the proportion of propionic acid for the 'diet S' periods and that found for the previous 'diet C' or 'diet F' periods. The results for acetic and butyric acids were less clear cut. Only for sheep no. 37, were changes in acetic acid consistently associated with changes in propionic and butyric acids.

$p H$, buffering capacity, ammonia and minerals. The $\mathrm{pH}$ was higher $(P<0.05)$ and the buffering capacity was lower for sheep given diet $\mathrm{F}$ than for those given diets $\mathrm{C}$ or $\mathrm{S}$ but values differed little between diets $\mathrm{S}_{\mathrm{p}}$ and $\mathrm{S}_{\mathrm{c}}$ (Table 3 ). For sheep receiving diet $\mathrm{S}$ there was no clear relationship between the rumen $\mathrm{pH}$ and the pattern of fermentation although for sheep no. 37 the decrease in the proportion of propionic acid between the first and second 'diet S' periods was associated with a pH change from $5 \cdot 30$ to 5.72 . Rumen ammonia values were very variable but tended to be lower for ' $\operatorname{diet} C$ ' and 'diet $S_{c}$ ' periods than for ' $\operatorname{diet} F$ ' and 'diet $S_{\mathfrak{f}}$ ' periods. For ' $\operatorname{diet} S_{\mathfrak{f}}$ ' and 'diet $S_{c}$ ' periods ammonia concentrations appeared to vary inversely with the molar proportion of propionic acid in a way analogous to that reported by Ishaque et al. (r97I). Statistical summary of these results was confounded by the between-animal differences, but for sheep no. 18 where the proportion of propionic acid was high in both periods, ammonia concentrations were II and $5^{6} \mathrm{mg} / 1$; for sheep no. 21 , where propionic acid was consistently low, the corresponding values were 249 and Ir I mg/l and for sheep no. 37 , where propionic acid decreased sharply from the first to the second periods, the values were $9 \mathrm{I}$ and $289 \mathrm{mg} / \mathrm{l}$.

The average concentrations of $\mathrm{Na}, \mathrm{K}$ and $\mathrm{Cl}$ were about 2060 , 1610 and $310 \mathrm{mg} / 1$ 
Table 4 . The volume $(l)$, outflow rate $(l / d)$ and clearance rate $(\% / h)$ of liquid in the rumen for two pairs of sheep receiving diets $F, C$ and $S$ in the order $F-S-C-S$ or $C-S-F-S$

$\begin{array}{lrrc}\text { Diet } & \text { Volume } & \text { Outflow rate } & \text { Clearance rate } \\ \mathrm{F} & 8 \cdot 57 & 18.09 & 8 \cdot 80 \\ \mathrm{C} & 6.02 & 5.98 & 5 \cdot 19 \\ \mathrm{~S}_{\mathrm{f}}^{*} & 7.27 & 10.95 & 6.68 \\ \mathrm{~S}_{\mathrm{c}}^{*} & 5.05 & 5.46 & 4.94 \\ \text { Standard error of } & & & \\ \quad \text { the difference } & & & \mathrm{I} \cdot 44\end{array}$

$\mathrm{F}$, forage mixture of chopped hay-ground, pelleted, dried grass $(92: 8, w / w) ; \mathrm{C}$ and $\mathrm{S}$, concentrate mixtures of ground barley-ground hay-flaked maize $(46: 24: 30$ and $56: 24: 20$, by wt respectively) (for details of the composition of diets, see Table $I$ ); $S_{f}$, diet $S$ given in the period following $\operatorname{diet} \mathbf{F}$; $S_{c}$, diet $S$ given in the period following diet $C$.

* Values for three sheep.

+ Standard error refers to the differences between diets $F$ and $C$ and between diets $S_{f}$ and $S_{c}$.

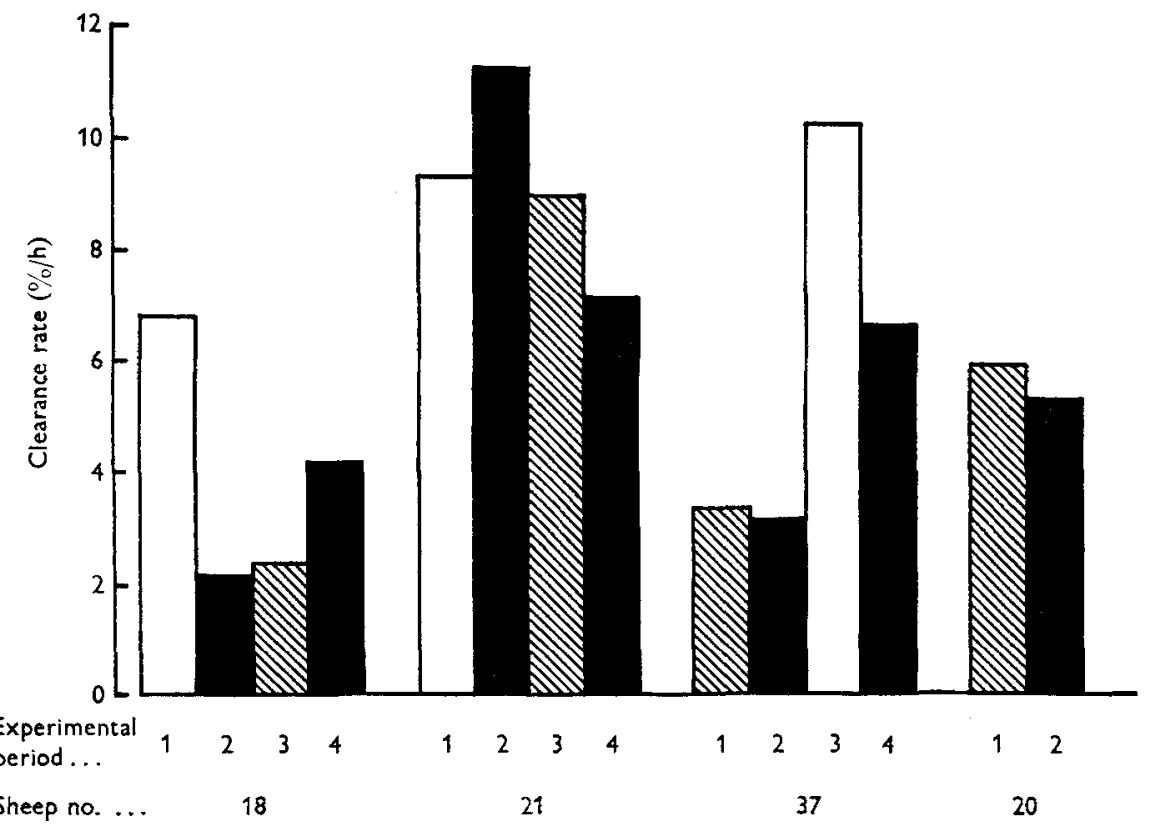

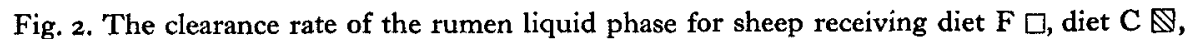
and diet $\mathrm{S}$. Diet $\mathrm{F}$ was a forage mixture of chopped hay-ground, pelleted, dried grass ( $92: 8$, $\mathrm{w} / \mathrm{w})$; diets $\mathrm{C}$ and $\mathrm{S}$ were concentrate mixtures of ground barley-ground hay-flaked maize ( $46: 24: 30$ and $56: 24: 20$, by wt respectively). For details of the composition of the diets, see Table I.

respectively and were very similar under all conditions; however $\mathrm{Ca}, \mathrm{Mg}$ and $\mathrm{P}$ concentrations were lower with diet $\mathrm{F}$ than with diets $\mathrm{C}$ or $\mathrm{S}$ and $\mathrm{Ca}$ values tended to be lower with diet $S_{c}$ than with diet $S_{\mathbf{f}}$. For sheep no. 37 there were no marked differences in the mineral composition of the rumen fluid between the two ' $\operatorname{diet} S$ ' periods except that the $\mathrm{Ca}$ concentration decreased from 108 to $64 \mathrm{mg} / \mathrm{l}$ and the $\mathrm{P}$ 
concentration increased from 1252 to $\mathrm{I} 630 \mathrm{mg} / \mathrm{l}$ from the first to the second periods respectively. There were however comparable changes for sheep no. 18 where the changes in fermentation between the two periods were quite unlike those for sheep no. 37 .

Rumen volume, outflow rate and clearance rate. Rumen volume (Table 4 ) was lower for $\operatorname{diet} \mathrm{C}$ than for $\operatorname{diet} \mathrm{F}$ and there were significant $(P<0.05)$ differences between these diets in outflow and clearance rates. Similarly volume and outflow and clearance rates were lower for the diet $S_{c}$ than for the diet $S_{f}$ although the differences between the diets were not statistically significant. All the results indicated the importance of the characteristics of the individual sheep and, for clearance rate particularly, these individual traits were very marked. The values for each sheep have been summarized in Fig. 2. The consistently high values for sheep no. 2I, the generally lower values for sheep no. I 8 and the pronounced change between periods in values for sheep no. 37 should be noted.

\section{DISCUSSION}

The present results confirm those of Ishaque et al. (197I) that with a mixed diet of ground barley, ground hay and flaked maize, there may be substantial variations in the mixture of short-chain fatty acids in the rumen between animals or in the same animal at different times. To summarize their results Ishaque and his colleagues distinguished two types of fermentation pattern characterized on the basis of their molar proportions of propionic acid or acetic plus butyric acids. In one group the molar proportions of acetic acid:propionic acid:butyric acid were $58: 15: 23$ and in the other $46: 33: 12$. Division of the present results for animals for the 'diet $\mathrm{S}$ ' periods into two groups in a similar way (on the basis of propionic acid values either above or below $25 \mathrm{~mol} /$ roo mol) gives corresponding fatty acid ratios $( \pm \mathrm{SE})$ of $60 \pm \mathrm{r} \cdot 2: 18 \pm \mathrm{r} \cdot 4: 18 \pm 0.6$ and $52 \pm 3 \cdot 9: 32 \pm 2 \cdot 4: I I \pm I \cdot 5$ respectively.

With regard to the influence of the pre-experimental ( $\mathrm{F}$ or $\mathrm{C})$ diet on the pattern of fermentation the results are equivocal. When the feeding sequence was $\mathrm{F}-\mathrm{S}-\mathrm{C}-\mathrm{S}$ the characteristics of the individual animal seemed to be a dominant factor in determining the pattern of fermentation in the 'diet S' periods. But, when the feeding sequence was $\mathrm{C}-\mathrm{S}-\mathrm{F}-\mathrm{S}$ the fermentation was more subject to variation and apparently more influenced by that in the previous period. It should of course be recognized that with a limited number of animals differences between feeding sequences could also be a reflexion of between-animal effects.

Because of the uncontrolled occurrence of the 'high' and 'low' propionic acid types of fermentation in the 'diet S' periods links between the pattern of fermentation and the environment in the rumen could not be investigated in the way originally planned. The main problem was to adequately distinguish in a statistical sense between differences associated with the fermentation pattern and those associated with the individual animal. Nonetheless, from the results for individual animals it seems unlikely that with this diet there are important relationships between the buffering capacity or the mineral composition of the rumen fluid and the pattern of fermentation. In addition, rumen $\mathrm{pH}$ does not appear to play a crucial role. In contrast, the 


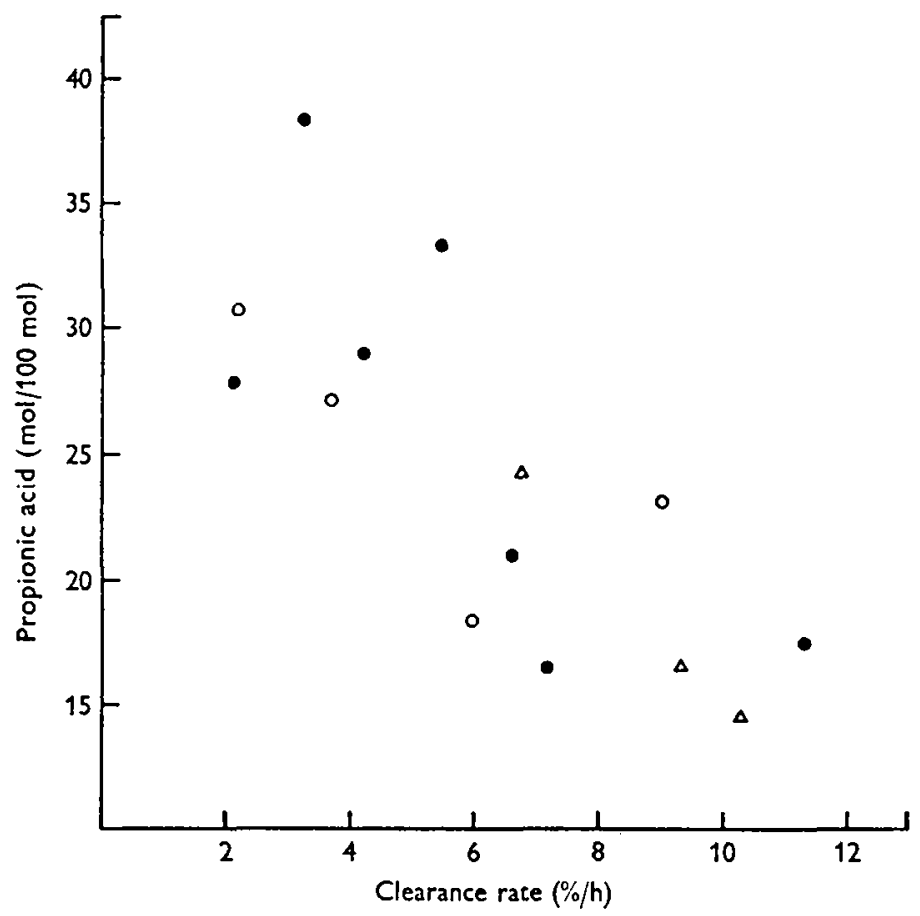

Fig. 3. The relationship between the molar proportion of propionic acid $(\mathrm{mol} / \mathrm{100} \mathrm{mol})$ in the rumen fluid and the clearance rate $(\% / h)$ of the rumen liquid phase for two pairs of sheep; $(O) \operatorname{diet} \mathrm{C}$, $(\bullet) \operatorname{diet} \mathrm{S}$ and $(\triangle)$ diet $\mathrm{F}$. Diet $\mathrm{F}$ was a forage mixture of chopped hay-ground, pelleted, dried grass $(92: 8, w / w)$; diets $C$ and $S$ were concentrate mixtures of ground barleyground hay-flaked maize $(46: 24: 30$ and $56: 24: 20$, by wt respectively). For details of the composition of the diets, see Table 1 , and for details of feeding regimen, see p. 449 .

movement of liquid through the rumen or more precisely, the clearance rate of the rumen pool does appear to be associated with the fermentation pattern. For sheep no. 2 i the clearance rate was high and the proportion of propionic acid was low, for sheep no. 8 the clearance rate was low and the proportion of propionic acid was high and for sheep no. 37 where there were changes in clearance rate between the 'diet $S$ ' periods there were inverse changes in the proportion of propionic acid.

Metabolic events within the rumen are influenced by the microbial population, the substrate fermented and the culture conditions. Differences between animals must in part reflect the influence of the anatomy and physiology of the individual on the culture conditions. The effect of variations between animals in the contribution of endogenous substrates to those fermented should be small. Examination, in these terms, of the pooled results for all animals given dict $\mathbf{S}$ confirms that there is a broad interrelationship between the molar proportion of propionic acid and the clearance rate (Fig. 3). Also, when the values for diets $\mathrm{C}$ and $\mathrm{F}$ are considered there are indications that the relationship may have a more general significance with respect to other diets.

This relationship between the clearance rate and the production of propionic acid is not necessarily causal. Nevertheless it is recognized that in vitro the numbers, types and metabolism of bacteria and protozoa can be influenced by the dilution rate 
(Powell, I958; Hobson, 1965 ; Meers, I97I) and it seems likely that similar considerations will apply in the rumen.

The authors wish to thank the Meat and Livestock Commission under whose auspices and with whose financial support this work was carried out.

\section{REFERENCES}

Annison, E. F. (1954). Biochem. F. 57, 400.

Bonting, S. L., Simon, K. A. \& Hawkins, N. M. (1960). Archs Biochem. Biophys. 95, 4 I6.

Campling, R. C. \& Freer, M. (I g66). Br. J. Nutr. 20, 229.

Christiansen, W. C., Woods, W. \& Burroughs, W. (1964). F. Anim. Sci. 23, 984.

Conway, E. J. (1957). Microdiffusion Analysis and Volumetric Error. London: Crosby, Lockwood \& Sons.

Davies, W. L. (1938). F. Dairy Res. 9, 327.

Emmanuel, B., Lawlor, M. J. \& McAleese, D. M. (I969). Br. F. Nutr. 23, 805.

Hobson, P. N. (1965). F. gen. Microbiol. 38, I67.

Hodgson, J. C. \& Thomas, P. C. (1972). Proc. Nutr. Soc. 31, 57 A.

Hungate, R. E. (1966). The Rumen and its Microbes. New York and London: Academic Press.

Ishaque, M., Thomas, P. C. \& Rook, J. A. F. (I97I). Nature New Biol. 23r, 253.

Meers, J. L. (1971). F. gen. Microbiol. 67, 359.

Minson, D. J. \& Cowper, J. L. (I966). Br. F. Nutr. 20, 757.

Powell, E. O. (1958). F. gen. Microbiol. 18, 259.

Smith, R. H. (1959). F. agric. Sci., Camb. 52, 72.

Storry, J. E. \& Millard, D. (1965). F. Sci. Fd Agric. 16, 417.

Tillman, A. D., Sirny, R. J. \& MacVicar, R. (1954). F. Anim. Sci. r3, 726.

Warner, A. C. I. (1966). F. gen. Microbiol. 45, 213.

Weston, R. H. \& Hogan, J. P. (I 967). Aust. F. agric. Res. 18, 789.

Youssef, F. G. \& Allen, D. M. (1966). F. Sci. Fd Agric. 17, 536. 